\title{
Multiplicar para crescer
}

\author{
Multiply to grow \\ Luciana Maria Borges da Matta Souza \\ Professora, Departamento de Pediatria/Universidade Estadual do Rio de Janeiro e Curso de Medicina/Universidade Estácio \\ de Sá (Unesa); coordenadora adjunta, Mestrado em Saúde da Família/Unesa. \\ luborges10@gmail.com
}

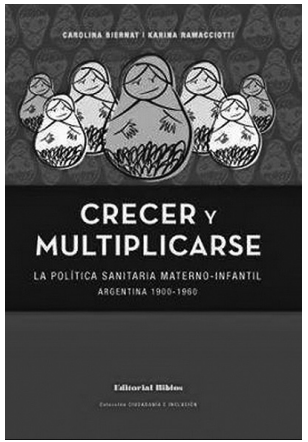

BIERNAT, Carolina; RAMACCIOTTI, Karina. Crecer y multiplicarse: la política sanitaria materno-infantil argentina, 1900-1960. Buenos Aires: Biblos. 2013. 165p.
$\mathrm{A}$ s políticas públicas voltadas para a infância desenvolvidas a partir do século XIX, inicialmente na Europa e EUA, sempre tiveram como objetivo básico a preservação das crianças, para garantia do crescimento populacional e constituição de mão de obra, necessária ao desenvolvimento econômico de uma nação. Crecer y multiplicarse: la política sanitária materno-infantil argentina, 1900-1960, obra organizada pelas historiadoras Carolina Biernat e Karina Ramacciotti, doutoras em história e ciências sociais, respectivamente, traz um conjunto de indagações sobre o processo de construção das políticas públicas de saúde argentinas, voltadas para o segmento materno-infantil, ocorrido na primeira metade do século XX. Por que nesse período? O recorte de análise privilegiou um momento sociopolítico-econômico no qual as certezas do crescimento populacional baseadas no aporte imigratório são postas em questão por um grupo que defendia o desenvolvimento da população a partir da preservação da vida e da saúde das mulheres argentinas e de seus filhos, o que foi, à época, denominado fator endógeno. A obra examina aspectos históricos dos debates e conflitos de interesses que ocorreram quando da criação dessas políticas, dissecando seus propósitos, seus sucessos, seus fracassos e seus limites ao serem colocadas em prática. Traz também reflexão sobre os bastidores políticos e econômicos que formavam o pano de fundo para o processo decisório não só na Argentina, mas também em outros países da América Latina, da construção da proteção social de mulheres e seus filhos.

O livro, além da introdução, foi estruturado em mais três capítulos, que trabalham diferentes aspectos do objeto de estudo: população e desenvolvimento econômico - a questão da crise demográfica; legislação de apoio à maternidade e as políticas de apoio à mulher-mãe e a seus filhos. De acordo com as autoras, o livro originou-se do desafio de converter a tarefa solitária do historiador em um projeto coletivo, momento em que abriram mão do seu ego 
e aprenderam a escutar e encarar o outro, nas diversas entrevistas e grupos que realizaram e que resultaram em críticas e sugestões ao material que foi, portanto, escrito a diversas mãos.

A introdução aborda os efeitos da política neoliberal dos anos 1990 e a crise de 2001, que trouxeram para a agenda política argentina um antigo problema, que se imaginava ter sido equacionado - a alta mortalidade materna e infantil. Partindo dessa situação, discorre-se sobre os programas desenvolvidos contemporaneamente para responder a essa questão, como o Seguro de Saúde Materno-infantil (2002), o Plano Nascer (2004) e a Assinatura Universal por Filho (2009) que, embora em conjunto tenham reduzido a alta mortalidade materna e infantil, não o fizeram de forma a causar grande impacto. Isso sugere, segundo as autoras, que o problema é mais complexo do que simplesmente garantir um pré-natal de qualidade, um parto seguro e recursos financeiros para famílias em situação de desemprego, estratégia largamente utilizada em países latino-americanos na atualidade. Surge no texto uma discussão, com fina ironia, sobre a criação de programas "inovadores" que têm a intenção de resolver problemas de longa data - há mais de um século a Argentina desenvolve estratégias para a redução da mortalidade infantil que, supostamente, deveria ter sido controlada por programas sociais preexistentes, apagados da memória do país por interesses políticos e ideológicos.

O texto traz como pressuposto a ideia de que as políticas sanitárias materno-infantis foram construídas em torno de duas preocupações essenciais: a alta mortalidade infantil e os baixos índices de natalidade, estes decorrentes de mudanças culturais que a sociedade argentina veio sofrendo ao longo do século, devido à urbanização e industrialização. Em certo momento o discurso estatal começa a ter um conteúdo moralizante, culpabilizando a mulher (como de costume!) por descuidar de seus filhos para se dedicar ao mercado de trabalho e por adotar um estilo de vida que estimulava a postergação do casamento, da primeira gravidez e consequentemente do número de filhos. O surgimento de um Estado com postura interventora nessas décadas inaugura um debate sobre a legitimidade da intervenção oficial em aspectos antes considerados de domínio privado.

No primeiro capítulo, intitulado "Muitos, porém sãos", é discutido o lugar central das ideias eugenistas da primeira metade do século XX, período caracterizado por pessimismo acerca do futuro demográfico da "raça branca", num contexto em que predominavam a alta mortalidade infantil, a baixa natalidade e a diminuição do fluxo imigratório (Bunge, 1984). Esse cenário traz um superdimensionamento do impacto da ideologia dominante nas decisões no setor público, numa lógica normalizadora e controladora, que entrelaçou propósitos econômicos, demográficos e sociais e acabou por construir o arcabouço da política social argentina (Biernat, Ramaciotti, 2008)

A política sanitária materno-infantil da Argentina nesse período é direcionada para a garantia do crescimento populacional (e sua necessidade premente!) - através de políticas de imigração e do aumento da fecundidade e da resolução da "questão social", constituída pelos efeitos perniciosos do processo de modernização que ocorre após as crises mundiais, caracterizada pelo risco de aumento da pobreza, marginalidade, criminalidade, insalubridade, problemas habitacionais e conflitos trabalhistas (Biernat, 2005). Tudo isso para assegurar a existência de um grande número de cidadãos e soldados saudáveis e compatíveis com a pretendida homogeneidade racial e integração social, defendida à época. Em conclusão, o objetivo desse capítulo é analisar as distintas tramas discursivas que influenciaram essa 
ideologia, a fim de conhecer o pensamento, os atores e as instituições que participaram da construção da política materno-infantil da Argentina nesse período.

O segundo capítulo, "Para mais filhos, melhores mães", é focado na análise do processo de construção das políticas de proteção das mulheres trabalhadoras em sua qualidade de mãe ou futura mãe. Apesar de os movimentos trabalhistas terem demandas para reconhecimento de outros direitos da mulheres, foi esse o único olhar dado pelo Estado à condição da mulher que trabalha, em consonância com a ideologia da época, já discutida. Propõe-se a revisar a distância entre as expectativas de uma sociedade a ser protegida em determinados aspectos e as capacidades efetivas de se pôr em funcionamento essa proteção social. Traz uma discussão sobre a preocupação do Estado argentino com relação à saúde das mulheres, mais especificamente em relação a sua capacidade reprodutiva, que se mostra presente desde as últimas décadas do século XIX (Coni, 1892). As políticas de proteção às mães, sejam as concretizadas, sejam as propostas, tinham propósitos fundamentalmente populacionistas e eugenistas, no sentido de diminuir os altos índices de mortalidade infantil, de prevenir a "degeneração da raça" ou de dar uma resposta à queda da natalidade, numa tentativa de "biologização da maternidade" (Nari, 2004). Eram conjugadas com as políticas de reordenamento social, melhora das condições de vida dos setores populares e moralização da população.

Para dar conta disso, existiam dois cenários privilegiados para essa intervenção estatal: o trabalho feminino e o processo de gestação, parto e criação dos filhos. O primeiro era considerado uma ameaça para a capacidade física reprodutiva das mulheres, por atrapalhar seu desenvolvimento corporal, deformar seu organismo e diminuir a possibilidade de surgimento da gravidez e de sua conclusão a contento. Além disso, o fato de a mulher trabalhar impediria a amamentação e criaria um obstáculo à constituição da figura materna. Apesar de todos esses obstáculos, a crescente e inevitável incorporação das mulheres ao mercado de trabalho gerava consenso em relação à necessidade da criação de legislação específica para regulamentar o trabalho assalariado, no sentido de compatibilizar duas funções da mulher: a de trabalhadora e a de mãe. O texto discorre sobre a relação do Estado com os sindicatos, que nem sempre se deu de forma pacífica. Enquanto o primeiro começa a pensar na proteção da mãe trabalhadora, o outro trabalha no sentido de apoiar a mulher trabalhadora que pode mãe não só para promover a redução da mortalidade infantil, mas também para reduzir os altos índices de mortalidade materna (Nari, 2004).

As autoras discorrem sobre os momentos distintos vivenciados na Argentina e nos países europeus em relação às políticas de proteção das trabalhadoras na sua qualidade de mães ou de futuras mães, capítulo importante na construção das intervenções sociais dos Estados contemporâneos. Enquanto a Argentina organiza políticas sociais em torno de um modelo pró-maternidade, a Itália, a França e a Espanha estabelecem leis pró-natalistas, nas quais surgem iniciativas de penalização do aborto e dos métodos contraceptivos, censura na educação sexual, imposto especial para pessoas solteiras e políticas de estímulo, como prêmios para nupcialidade e natalidade, além de empréstimos e isenções tributárias para famílias numerosas (Bock, Thane, 1991). Na Argentina, o aborto e os métodos contraceptivos não são penalizados energicamente, nem são incorporadas à legislação medidas de estímulo à natalidade, apesar 
de ser esse o discurso. Em seu lugar, nos anos 1920 e 1930 foram criadas várias estratégias que tendem a proteger a família e a desvincular a mulher do mercado de trabalho.

Nesse momento, partindo de diferentes pressupostos, socialistas e católicos são apresentados diversos projetos legislativos que se propõem a reforçar as "condições de reprodução" consideradas o "pilar fundamental da sociedade". Mulheres com o papel exclusivo de reprodutoras... Isso direciona a uma política de constituição de um salário para o homem que seja suficiente para o sustento de sua mulher e seus filhos, reforçando a estrutura patriarcal, fenômeno que se vê ainda presente nos dias de hoje, quando constatamos que, em muitos cargos, o salário dos homens se mostra maior do que o das mulheres e as mesmas são preteridas quando concorrem com os homens. Por outro lado, no sentido de proteger as mulheres e seus filhos, promove-se a organização de um sistema nacional de assistência sanitária e social materno-infantil, criação de inúmeras instituições para controlar a saúde dos cônjuges através de exames pré-nupciais, estímulo ao aleitamento materno, amparo às mães solteiras e crianças órfãs e impulsiona-se a educação de mulheres na "arte de ser mãe" (Marpons, abr. 1935). Essa não é uma prerrogativa da Argentina, visto que observamos movimentos semelhantes na base da organização de programas maternoinfantis em diversas partes do mundo, seja por uma preocupação de aperfeiçoamento da raça ou para garantir a eficiência econômica do fator humano (como ocorreu na Alemanha, no Reino Unido ou nos EUA), seja pelo processo de diminuição dos índices de natalidade (ocorrido na França) ou por todos esses motivos somados (como ocorreu em alguns países latino-americanos, como no Chile - vanguarda em matéria de seguro social -, no Uruguai e no Brasil).

No Brasil, a Consolidação das Leis do Trabalho, em 1943, estabeleceu a impossibilidade de demissão de mulheres grávidas; proibiu seu trabalho seis semanas antes e seis semanas após o parto, com permanência de salário integral; regulamentou descansos para a amamentação e estimulou a criação de ambientes de lactação/amamentação dentro das fábricas, proposta malsucedida até os dias de hoje (Freire, 2009). O que fica claro é que as políticas sociais e sanitárias para mães e seus filhos na Argentina são fruto de uma conflituosa relação entre o Estado e as demandas provenientes de diversos grupos políticos, sociais e acadêmicos.

O capítulo também discute a criação da Caixa de Maternidade, em 1934, modelo de política de saúde que se propôs oferecer às trabalhadoras licença remunerada a partir das últimas quatro semanas de gestação até seis semanas após o parto, medida que encontrou dificuldades de concretização política, visto que se restringiu à cidade de Buenos Aires e arredores. Interessante notar que na atual legislação argentina pouca coisa foi modificada desde então, só tendo ocorrido uma pequena ampliação da licença para duas semanas antes do término da gestação e o direito de intervalo para amamentação (Castel, 2008). Também é discutido o seguro social de saúde advogado nos primeiros anos do peronismo. Para o modelo de Estado peronista "rende mais à sociedade uma mulher cuidando de sua casa e tendo filhos do que os valores econômicos que possa produzir num emprego" (Rodriguez, 1947, p.3). Esses conjuntos de medidas transformam a maternidade em veículo por meio do qual as mulheres são incorporadas à ordem política, em um momento carregado de tensões sociais, mas que permite a ampliação dos seus direitos sociais e políticos e culmina na obtenção de sua capacidade civil plena. 
O terceiro e último capítulo, intitulado "Mães e filhos na órbita estatal", tem como objetivo estudar a mudança de dois aspectos centrais das políticas assistenciais da Argentina na primeira metade do século XX: o deslocamento do olhar para o sujeito a ser protegido, que deixa de ser a criança para ser o binômio mãe-filho; e a mudança do ator principal na organização dessa assistência, que deixa de ser o setor privado e o poder municipal para ser centralizado pelo poder estatal, ultrapassando as políticas inicialmente criadas para a cidade de Buenos Aires, por meio de um processo lento e conflituoso no período do peronismo clássico. Isso representa uma mudança na forma de pensar as estratégias para resolução das preocupações demográficas e sociais, assegurando, entre outras medidas, modificações socioambientais através de políticas de higiene, sociais e educacionais. As autoras apresentam os diversos dispositivos públicos e privados criados ao longo do período, como, por exemplo, o Patronato da Infância (entidade filantrópica) e a Diretoria da Primeira Infância, vinculada ao Departamento Nacional de Higiene, com seus dispensários de lactantes, institutos de puericultura e centros sanitários de internação, oriundos do poder estatal, inicialmente em Buenos Aires. O sucesso obtido na capital federal na redução da mortalidade infantil é atribuído ao Estado, que passa a reclamar para si a organização da tutela de mães e filhos, mediante a regulação do trabalho feminino, seus processos de gestação, parturição e criação de seus filhos. Não devemos ignorar que a intenção de solucionar a "crise populacional" enfrentada pela Argentina foi o gancho para um projeto político muito mais ambicioso: dotar o Estado de uma organização centralizada e racional de assistência sanitária e social (Guy, 1998; Scarzanella, 2003). Ao longo de todo o capítulo é apresentada de forma bastante detalhada uma série de leis, portarias e documentos que tentam organizar a rede de apoio social e à saúde da mulher e seu filho em território argentino, caracterizada por superposição de tarefas e jurisdições e por escassez de recursos financeiros e humanos.

Em suma, a relevância desse texto é iluminar um momento de configuração da história argentina, apagado pela "revolução libertadora". Iniciado com o golpe de Estado em 1955, esse movimento tenta anular todos os vestígios do período peronista e se propõe a obscurecer todas as discussões técnicas e políticas da primeira metade do século XX. Inaugura uma política materno-infantil argentina ainda preocupada com questões demográficas e sociais, mas baseada em acordos e recomendações internacionais, como a Ata de Bogotá e a Carta de Punta del Leste, tornando invisível toda a complexa política materno-infantil articulada até aquele momento. Isso nos faz pensar que não somente os argentinos, mas muitos povos são vítimas dessa perda de memória, que não nos permite ver as semelhanças e diferenças do passado e do presente e nos faz viver progressos e retrocessos ao longo da história.

\section{REFERÊNCIAS}

BIERNAT, Carolina.

La eugenesia argentina y el debate sobre el crecimiento de la población en los años de entreguerras. Cuadernos del Sur (Historia), n.34, p.251-273. 2005.

BIERNAT, Carolina; RAMACIOTTI, Karina. La tutela estatal de la madre y el niño en la Argentina: estructuras administrativas, legislación y cuadros técnicos, 1936-1955.

História, Ciências, Saúde-Manguinhos, v.15, n.2, p.331-351. 2008.

BOCK, Gisela; THANE, Pat.

Maternidad y políticas de género. Madrid: Cátedra. 1991. 
BUNGE, Alejandro.

Una nueva Argentina. Buenos Aires: Hyspamérica. 1984.

CASTEL, Robert.

La inseguridad social: qué es estar protegido? Buenos Aires: Manantial. 2008.

CONI, Emilio.

Patronato y asistencia de la infancia en la Capital Federal. Buenos Aires: s.n. 1892.

FREIRE, Maria Martha de Luna.

Mulheres, mães e médicos: discurso maternalista no Brasil. Rio de Janeiro: Editora FGV. 2009.

GUY, Donna.

The Pan American Child Congress, 1916-1942: Pan Americanism, Child Reform, and the Welfare State in Latin America. Journal of Family History, v.23, n.3, p.272-291. 1998.
MARPONS, Josefina.

Protección a la maternidad. Vida Femenina. p.8-9. abr. 1935.

NARI, Marcela.

Políticas de maternidad y maternalismo político: Buenos Aires, 1890-1940. Buenos Aires: Biblos. 2004.

RODRIGUEZ, Germinal.

El trinomio médico-social. Archivos de la Secretaria de Salud Pública, v.5, n.3, p.3. 1947.

SCARZANELLA, Eugenia.

Los pibes en el palacio de Ginebra: las investigaciones de la Sociedad de las Naciones sobre la infancia latinoamericana (1925-1939). Estudios Interdisciplinarios de America Latina y el Caribe, v.14, n.2. Disponível em: http://www7. tau.ac.il/ojs/index.php/eial/article/view/833. Acesso em: 20 fev. 2015. 2003. 